\title{
Comparative Analysis of Basic Performance of Self-made Butyl Rubber and Imported Butyl Rubber
}

\author{
Zhongqiu Ai ${ }^{\text {a,b }}$, Jin Liu ${ }^{c}$, Wenzhong Sun ${ }^{\mathrm{a}}, \mathrm{Li} \mathrm{Wei}^{\mathrm{a}}{ }^{\mathrm{a}}$ \\ ${ }^{a}$ Dalian Polytechnic University, Dalian 110634, China \\ ${ }^{\mathrm{b}}$ China National Petroleum Corporation, Dongcheng District 100007, Beijing, China

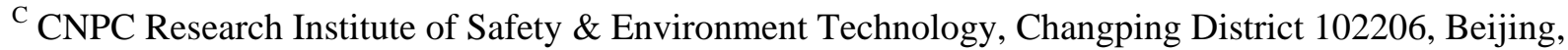 \\ China
}

Keywords: Butyl rubber (IIR)

\begin{abstract}
In this article, the performance comparison evaluation of self-made solution process Butyl rubber (IIR) LH-1 and two kinds of imported Butyl rubber(IIR) (solution process IIR ET-110 and slurry process IRR EJ-120), the results showed that the self-made LH-1 had some differences with the contrast sample ET-110 and EJ-120 on the ingredients of gum. LH-1 compound and vulcanizate are comparable in various properties to the comparison samples ET-110 and EJ-120, comprehensive performance of LH-1 is closer to EJ-120.
\end{abstract}

Butyl rubber (IIR) is the product of the polymerization reaction of isobutylene and isoprene under the action of a catalyst. Due to the high degree of saturation of butyl rubber molecular chains and the dense arrangement of methyl groups in the molecular chains, the airtightness, heat resistance and ozone resistance of butyl rubber are superior to those of natural rubber and styrene butadiene rubber. At the same time, butyl rubber also has excellent weather resistance, heat resistance, alkali resistance, large damping and easy to absorb energy and other characteristics. Butyl Rubber is widely used in making inner tubes, water tires, vulcanization bladders, tire inner liners, sidewalls, wire and cable, waterproof building materials, shock absorbing materials, medicinal stoppers, foods (gum bases), rubber dams, antivirus kits, adhesives, Inner tube valve core, anti-corrosion products, dock fenders, bridge support pads, and heat-resistant conveyor belts, etc.

The industrial production of butyl rubber started in the 40s of the last century. Since then, the production of butyl rubber has developed rapidly in the world's major industrialized countries ${ }^{[1]-[3]}$. In 2007, the butyl rubber production capacity all over the world was 1.17 million tons, of which the dominant butyl rubber manufacturers were Exxon and LANXESS. They not only have large output, but also have the most advanced technology. As a rising star, Russia's technological level and product quality have been continuously improved and its total production capacity has reached nearly 200,000 tons. In recent years, the world's butyl rubber production capacity has grown steadily. In 2017, it was 1.776 million tons, and the total production capacity in 2020 is expected to reach 2.5 million tons.

The butyl rubber research and development in China began in the 1960s. At present, mainland of China is the largest butyl rubber producer in China with a production capacity of 395,000 tons, accounting for $22.24 \%$ of the world's total production capacity. The consumption structure of butyl rubber in China is: the tire field accounts for about $84 \%$ of the total consumption, medical bottle stoppers account for about $11 \%$, and other aspects account for about $5 \%$. Affected by the policy of encouraging the development of radial tires, the demand for butyl rubber in the tire industry has grown rapidly. The butylation of pharmaceutical bottles is the second largest market for butyl rubber in China. It is expected that the total demand will reach about 500-550 thousand tons by 2020. In consideration of the serious shortage of butyl rubber production in China, some petrochemical companies and private capitals are investing more in butyl rubber ${ }^{[4]}$.

This research project compares and analyzes the basic performance between the small-scales test samples of elf-made butyl rubber and imported butyl rubber. 


\section{Test}

\subsection{Raw materials}

The test sample was a self-made solution of butyl rubber sample LH-1 and two imported comparative butyl rubber samples ET-110 and EJ-120.

\subsection{Test basis and content}

The test is mainly based on the Chinese Petrochemical Industry Standard "Isobutylene-isoprene rubber (IIR) evaluation method" SH/T 1717-2008 (idt ISO 2302:2005), and at the same time, according to the request of the client and the sample, the actual situation has been adjusted appropriately.

Test items include: 1 Physical and chemical properties of raw rubber, including ash, volatiles, copper content, iron content and molecular weight and molecular weight distribution. 2 The properties of the mix, including Mooney viscosity, Mooney scorch, and cure properties. 3. Vulcanizate properties, including rubber hardness, tensile strength, elongation at break, tensile stress, tear strength. 4 Other properties of vulcanizates, such as resilience, brittle temperature, compression set, compression heat and swelling index.

\subsection{Test Formula and Mixing Process}

Test Formula: Use the standard test formulation of Chinese Petrochemical Industry Standard "Isobutylene - Isoprene Rubber (IIR) Evaluation Method" SH/T 1717-2008 (idt ISO 2302:2005). The specific formulation is shown in Table 1.

Mixing process: Mixing with an open mill, and the process is performed according to the mixing method A in the SH/T 1717-2008 standard. The open mill is model XK-160 with 2.5 times the amount of compounding.

Table 1 Recipe Table

\begin{tabular}{cccc}
\hline Recipe No. & LH-1 & ET-110 & EJ-120 \\
\hline LH-1 & 100.0 & & \\
ET-110 & & 100.0 & \\
EJ-120 & & & 100.0 \\
Stearic acid & 1.00 & 1.00 & 1.00 \\
Zinc Oxide & 3.00 & 3.00 & 3.00 \\
Industrial Reference Carbon & 50.00 & 50.00 & 50.00 \\
Black (IRB No.7) & 1.00 & 1.00 & 1.00 \\
Accelerator TMTD & 1.75 & 1.75 & 1.75 \\
Sulfur & 156.75 & 156.75 & 156.75 \\
Total & &
\end{tabular}

\subsection{Main Test Methods and Instruments}

1) Rubber compounding: According to the standard SH/T 1717-2008, mixing is performed using an open roll mill. The mixing was performed on an XK-160 open mill.

2) Vulcanization characteristics: The vulcanization characteristics of the rubber compound are tested with MR-C3 type of rotorless vulcanizer. The test temperature is $160^{\circ} \mathrm{C}$, the vibration rate is $1.7 \mathrm{~Hz}$, and the amplitude is $1^{\circ}$.

3) Mooney Viscosity, Mooney Relaxation and Mooney Scorch: Tested with a M200E Mooney viscometer for a relaxation time of $120 \mathrm{~s}$.

4) Compression set: compression ratio $25 \%$, test temperature $100^{\circ} \mathrm{C}$, time $24 \mathrm{~h}$.

5) Tensile Strength, Tensile Elongation, Tensile Deformation, Tensile Stress: Adopting T2000E Material Tensile Testing Machine made by Beijing Youshen Electronic Instrument Co., Ltd. 
According to GB/T 528-2009 "Vulcanizate or Thermoplastic Rubber Pulling", the determination of the stress-strain properties was carried out by the relevant tests.

6) Tear strength: The T2000E material tensile testing machine made by Beijing Youshen Electronic Instrument Co., Ltd. was used in accordance with GB/T 529-2008 "Determining the tear strength of vulcanized rubber or thermoplastic rubber (trousers, right angles and crescents) ".

7) Swelling Index Test: Tested in accordance with HG/T 3870-2008 "Test Method for Swelling Index of Vulcanized Rubber."

8) Compression of heat: Y3000E compression heat tester made by Beijing Yonsei Electronic Instrument Co., Ltd. is used in accordance with GB/T 1687.3-2016 "Vulcanized rubber in the flexion test temperature rise and fatigue resistance determination - Part 3: Compression Flexibility test (constant strain type) ".

9) Low-temperature brittleness: Tested in accordance with GB/T 1682-2014 "Testing method for low-temperature brittleness of vulcanized rubber, single sample method".

10) Other tests are conducted in accordance with the relevant national or industry standards.

\section{Results and Discussion}

\subsection{Raw rubber performance}

\subsubsection{Chemical Analysis}

The experimental data of raw rubber chemical analysis is shown in Table 2. From the results, it can be seen that the volatile content of the LH-1 sample is significantly higher than that of the comparative sample. The ash content of the LH-1 sample is comparable to that of the comparative sample ET110 (ET110 is slightly higher than the LH-1 sample), while it is quite different from the EJ-120.

Table 2 Chemical analysis data of raw rubber

\begin{tabular}{cccc}
\hline Project & LH-1 & ET-110 & EJ-120 \\
\hline Volatile content \% & 0.18 & 0.02 & 0.05 \\
Ash Content \% & 0.15 & 0.21 & 0.08 \\
\hline
\end{tabular}

\subsubsection{Metal Content Analysis}

We used atomic absorption spectrometry to analyze the copper and iron contents of LH-1 samples and comparative samples. The experimental results are shown in Table 3.

Table 3 Determination of metal content in raw rubber

\begin{tabular}{ccccc}
\hline Project & LH-1 & ET-110 & EJ-120 \\
\hline Copper content & $\%$ & 0.00061 & 0.00030 & 0.00019 \\
Iron content $\%$ & 0.0027 & 0.00056 & 0.00029 \\
\hline
\end{tabular}

The content of copper and iron in LH-1 samples was higher than that of ET-110 and EJ-120, especially for the iron content. In the two comparative samples, the copper and iron content in EJ-120 raw gum was the lowest.

\subsubsection{Molecular Weight and Its Molecular Weight Distribution}

Gel chromatography GPC was used to determine the molecular weight and molecular weight distribution of LH-1 and two comparative samples ET-110 and EJ-120. The test results are shown in Table 4 which shows that the number-average molecular weight $\bar{M}$ and weight-average molecular weight Mw $\overline{M w}$ of the LH-1 sample are slightly lower than the comparative samples ET-110 and EJ-120. The difference in the molecular weight distribution of the three butyl rubbers was not significant. The LH-1 sample was comparable to the EJ-120 and the ET-110 was slightly lower. 
Table 4 Butyl Rubber Molecular Weight and Molecular Weight Distribution

\begin{tabular}{cccc}
\hline $\begin{array}{c}\text { Molecular weight and } \\
\text { molecular weight distribution }\end{array}$ & LH-1 & ET-110 & EJ-120 \\
\hline $\bar{M}$ & 234058 & 280124 & 265976 \\
$\bar{M}$ & 613825 & 624234 & 729944 \\
$\bar{M} \bar{M} / \overline{M n}$ & 2.62 & 2.23 & 2.74 \\
\hline
\end{tabular}

\subsection{Compound performance}

\subsubsection{Compound properties}

In the mixing process, the three rolls have good packet roller properties, and both have good carbon black and good mixing speed of the auxiliary. The surface of the film is relatively smooth and has a good gloss.

\subsubsection{Mooney viscosity, Mooney relaxation and Mooney scorch}

Both the Mooney viscosity and Mooney relaxation of a compound are the methods to characterize rubber processing properties. Mooney relaxation area A can comprehensively measure the processing behavior of the compound. The greater the stress relaxation area A, the worse the processing performance, and vice versa.

Mooney scorch mainly reflects the processing safety of the rubber material and ensures that the compound does not show early vulcanization during the processing to ensure the performance of the rubber product. The Mooney scorch time t5 indicates that the rubber processing is safe. The Mooney viscosity, Mooney relaxation, and Mooney scorch experimental data for the three butyl rubber compounds are shown in Table 5.

Table 5 Mooney Viscosity, Mooney Relaxation, and Mooney Scorch in Blends

\begin{tabular}{|c|c|c|c|c|}
\hline \multicolumn{2}{|c|}{ Project } & LH-1 & ET-110 & EJ-120 \\
\hline \multicolumn{2}{|c|}{$\begin{array}{c}\text { Compound Mooney viscosity } \\
\text { ML }(1+8) 125^{\circ} \mathrm{C}\end{array}$} & 66 & 68 & 66 \\
\hline \multirow{5}{*}{ Mooney relaxation } & $\mathrm{t} 70$ & 6 & 6 & 6 \\
\hline & $\mathrm{t} 80 \quad \mathrm{~s}$ & 8 & 8 & 8 \\
\hline & Interception $\mathrm{K}$ & 61.7 & 64.0 & 62.5 \\
\hline & Slope a & -0.58 & -0.69 & -0.66 \\
\hline & Area A & 953 & 711 & 743 \\
\hline \multirow{3}{*}{$\begin{array}{l}\text { Mooney Scorch } \\
\quad\left(120^{\circ} \mathrm{C}\right)\end{array}$} & t5 $\min$ & 19 & 22 & 20 \\
\hline & $\mathrm{t} 35 \min$ & 24 & 28 & 26 \\
\hline & $\Delta \mathrm{t} 30 \quad \min$ & 5 & 6 & 6 \\
\hline
\end{tabular}

As can be seen from Table 5:

1) The Mooney viscosities of the three blends are comparable and there are no significant differences. The LH-1 Mooney relaxation area is higher than ET-110 and EJ-120.

2) The Mooney scorch time of LH-1 compound is similar to that of EJ-120, which is slightly shorter than that of ET-110. However, it still has good processing safety and can meet the requirements of rubber processing.

\subsubsection{Vulcanization characteristics}

The rubber vulcanization characteristics test was carried out at $160^{\circ} \mathrm{C}$ according to the requirements of the "Isobutylene-isoprene rubber (IIR) evaluation method" SH/T 1717-2002 (idt ISO 2302: 1995) standard. Table 7 lists the parameters required by the standard. ML is the minimum torque, which reflects the lowest viscosity of the rubber at the test temperature. If ML is 
low, the rubber will have better fluidity during the vulcanization induction phase of the vulcanization process, and can fill the rubber more fully. $\mathrm{MH}$ is the maximum torque, which reflects the maximum degree of cross-linking that the compound can achieve under the curing conditions. In addition, t10 and t90 are the time required for the compound to reach $10 \%$ and $90 \%$ of (MH-ML) from the lowest torque (ML). Vc is the vulcanization speed index. The larger Vc, the faster the vulcanization speed of the rubber material.

It can be seen from the test results in Table 6 that:

1) The ML and MH of the LH-1 compound are similar to those of EJ-120, the ML and MH of the ET-110 compound are slightly lower.

2) The t10, t90, and Vc of LH-1 compound are similar to those of ET-110 and EJ-120, with no significant difference.

Table 6 Compound vulcanization characteristics

\begin{tabular}{|c|c|c|c|c|}
\hline \multicolumn{2}{|c|}{ Project } & LH-1 & ET-110 & EJ-120 \\
\hline \multirow{6}{*}{$\begin{array}{c}\text { MDR } \\
\left(160^{\circ} \mathrm{C}\right)\end{array}$} & ML $\quad \mathrm{N} \cdot \mathrm{m}$ & 0.95 & 0.89 & 0.94 \\
\hline & $\mathrm{MH} \quad \mathrm{N} \cdot \mathrm{m}$ & 3.37 & 3.07 & 3.33 \\
\hline & t 10 min & 2.15 & 2.82 & 2.53 \\
\hline & $\mathrm{t} 50 \quad \min$ & 6.55 & 6.20 & 6.38 \\
\hline & $\mathrm{t} 90 \mathrm{~min}$ & 23.85 & 23.85 & 23.25 \\
\hline & Vc $\min -1$ & 4.43 & 4.52 & 4.60 \\
\hline
\end{tabular}

\subsection{Vulcanizate properties}

The main physical properties of vulcanizates include: resilience, compression heat, tear strength, brittle temperature, compression set and swelling index and aging resistance and other tests.

\subsubsection{Vulcanizates tensile stress-strain properties}

The tensile stress-strain test results of vulcanizates are shown in Table 7.

Table 7 Tensile stress-strain properties of vulcanizates

\begin{tabular}{ccccc}
\hline \multicolumn{2}{c}{ Recipe No. } & LH-1 & ET-110 & EJ-120 \\
\hline \multicolumn{4}{c}{ Vulcanization conditions: } & $150^{\circ} \mathrm{C} \times 80 \mathrm{~min}$ \\
\hline Hardness & Shore A & 68 & 67 & 69 \\
Elongation at break & $\%$ & 440 & 416 & 449 \\
Tensile strength & $\mathrm{MPa}$ & 16.2 & 15.9 & 16.2 \\
100\% Definite Stress MPa & 2.63 & 2.60 & 2.54 \\
300\% Definite Stress MPa & 10.5 & 10.7 & 10.3 \\
Breaking permanent deformation \% & 28 & 24 & 24 \\
\hline
\end{tabular}

From the data in Table 7, you can see:

1) The tensile stress-strain properties of LH-1 vulcanizate and comparative samples ET-110 and EJ-120 vulcanizates were similar, such as hardness, tensile stress, tensile strength, and tensile elongation at break, have no significant differences.

2) The tensile permanent deformation of LH-1 vulcanizate is slightly higher than that of the comparative samples ET-110 and EJ-120.

3) The tensile stress and strain properties of LH-1 vulcanizate are similar to those of EJ-120.

\subsubsection{Vulcanizate Physical Properties}

The physical properties of vulcanizates are shown in Table 8. From the data in Table 8, we can see:

1) The resilience, tear strength, and brittle temperature of the LH-1 vulcanizate are comparable to 
those of the comparative samples ET-110 and EJ-120, with no significant difference.

2) The compression set of LH-1 vulcanizate is slightly greater than that of the comparative samples ET-110 and EJ-120 vulcanizates.

3) LH-1 vulcanizate compression heat generation and final compression ratio is slightly lower than EJ-120, slightly higher than ET-110, but the permanent deformation is slightly bigger than ET-110 and EJ-120.

Table 8 Physical properties of vulcanizates

\begin{tabular}{|c|c|c|c|}
\hline Project & LH-1 & ET-110 & EJ-120 \\
\hline Resilience & 13 & 14 & 13 \\
\hline Tear strength $\mathrm{kN} / \mathrm{m}$ & 38.4 & 38.2 & 38.9 \\
\hline Compression set $\%$ & 60.8 & 58.6 & 59.7 \\
\hline Brittle temperature ${ }^{\circ} \mathrm{C}$ & -44 & -44 & -45 \\
\hline \multicolumn{4}{|c|}{ Compression heat stroke: $4.45 \mathrm{~mm}$, load: $1.0 \mathrm{MPa}$, temperature: $55^{\circ} \mathrm{C}$} \\
\hline Final compression ratio \% & 13.3 & 12.7 & 14.5 \\
\hline Compression of heat ${ }^{\circ} \mathrm{C}$ & 32.7 & 31.9 & 33.2 \\
\hline Permanent deformation \% & 6.85 & 5.75 & 5.50 \\
\hline
\end{tabular}

\subsubsection{Aging performance}

The hot air accelerated aging test was performed in an LP-61 type aging box. The aging condition is $100^{\circ} \mathrm{C} \times 24$ hours. The storage period after the aging was 16 hours and then the physical properties of the aged specimens were tested and compared with the unaged specimens.

Table 9 shows the aging properties of vulcanized rubber. It can be seen that the change rate of tensile strength and elongation at break of the three vulcanizates after aging are similar, and the rate is small, indicating that the aging resistance of three butyl rubber vulcanizates is comparable good, and the anti-aging properties of the three vulcanizates are basically equivalent ${ }^{[5]}$.

Table 9 Aging properties of vulcanizates

\begin{tabular}{|c|c|c|c|c|}
\hline \multicolumn{2}{|c|}{ Recipe No } & LH-1 & ET-110 & EJ-120 \\
\hline \multirow{2}{*}{$\begin{array}{l}\text { Elongation at } \\
\text { break \% }\end{array}$} & before aging & 440 & 416 & 449 \\
\hline & After aging & 398 & 378 & 419 \\
\hline \multicolumn{2}{|c|}{$\begin{array}{l}\text { Tensile elongation change } \\
\text { rate } \%\end{array}$} & -10 & -9 & -7 \\
\hline \multirow{2}{*}{$\begin{array}{l}\text { Tensile strength } \\
\mathrm{MPa}\end{array}$} & before aging & 16.2 & 15.9 & 16.2 \\
\hline & After aging & 15.7 & 15.3 & 15.9 \\
\hline \multicolumn{2}{|c|}{ Tensile Strength Change Rate \% } & -3 & -3 & -2 \\
\hline
\end{tabular}

\subsubsection{Swelling Index}

Vulcanized rubber can only swell not dissolve in organic solvents. The size of vulcanizate swelled in organic solvents is closely related to its crosslinking density. The swelling index is inversely proportional to the crosslinking density. The greater the swelling index, the smaller the cross-linking density; conversely, the smaller the swelling index, the greater the cross-linking density.

Table 10 Butyl Rubber Swelling Index Test Data

\begin{tabular}{cccc}
\hline Project & LH-1 & ET-110 & EJ-120 \\
\hline Swelling Index & 2.14 & 2.26 & 2.29 \\
\hline
\end{tabular}


Table 10 shows butyl rubber swelling index. It can be seen that the swelling index of LH-1 vulcanizate is the smallest and its cross-linking density is the largest; the swelling index of ET-110 and EJ-120 vulcanizates is slightly larger than that of LH-1 vulcanizates, indicating their smaller cross-linking density. Under the same vulcanization system and vulcanization conditions, the crosslink density of LH-1 is slightly higher than that of ET-110 and EJ-120.

\section{Conclusion}

1) Compared with the comparison samples ET110 and EJ-120, the LH-1 sample produced higher volatile content and ash content comparable to the comparative sample ET110 but higher than EJ-120.

2) The content of copper and iron in crude rubber of LH-1 sample are higher than that of the comparative samples ET110 and EJ-120, especially iron content.

3) The molecular weight of the LH-1 sample was slightly lower than that of the comparative samples ET110 and EJ-120, but the molecular weight distributions of the three butyl rubbers were comparable.

4) Mooney viscosity of LH-1, ET110, and EJ-120 is comparable, and LH-1 Mooney relaxation area is higher than ET-110 and EJ-120. The Mooney scorch time of LH-1 compound is similar to that of EJ-120 and is slightly shorter than ET-110, but it still has good processing safety and can meet the requirements of rubber processing.

5) LH-1 vulcanizate tensile strength, elongation at break, tensile stress, hardness, elasticity, tear strength, aging resistance and brittle temperature and other properties similar to ET110 and EJ-120, no significant difference. The compression set of the LH-1 vulcanizate is slightly greater than that of the comparative samples ET-110 and EJ-120 vulcanizates. LH-1 vulcanizate compression heat and final compression ratio is slightly lower than EJ-120, slightly higher than ET-110, but the permanent deformation is slightly larger than ET-110 and EJ-120 .

6) Under the same conditions, the crosslinking density of LH-1 vulcanizate is slightly higher than that of ET-110 and EJ-120.

In summary, the self-made LH-1 has some differences in the components of raw rubber from the comparative samples ET-110 and EJ-120. The LH-1 compound and vulcanizate are comparable to the comparative samples ET-110 and EJ-120 in various properties. The overall performance of LH-1 is closer to EJ-120.

\section{References}

[1]Cui Xiaoming, Supply and demand status and development analysis of Chinese halogenated butyl rubber, [J]. China Petro and Chemical Engineering Economic Enalysis.2017(11):61-64.

[2]He Li, The discussion on market development prospect of butyl synthetic, [J]. Rubber and Plastics Resources Utilization,2017(3): 19-28.

[3]Qian Bozhang, The butyl synthetic analysis of domestic and foreign markets,[J]. Shanghai Chemical Engineering,2010,35(1):34-37.

[4]Wang Yan,Yuan Hongtu,Lu Lili. The butyl synthetic rubber production present situation and development prospect, [J]. Chemical Enterprise Management,2017(17):58.

[5]Ding Pingping, The influence of test temperature and parking time on the processing properties of rubber materials, [J].Tire Industry,2004,24(8):497-499. 